faculty/staff newsletter; the University Libraries, a quarterly library publication; and a number of departmental newsletters. The MSU News Bulletin proved to be the second most effective publicity method. Copies of the flyer were made available to the MSU branch libraries, and to the Main Library reference desks. Confirmation of registrations was also time-consuming but resulted in much better attendance. Many people attended more than one session and professors encouraged their graduate students to attend particular sessions. In this way, the seminars have begun to publicize themselves.

These seminars have had a variety of benefits, some of them indirect. Unquestionably, the participants learn a great deal and come back the next term if they were drawn to a seminar relevant to their needs. The program as a whole provides very good public relations for the library. Like other instructional programs, this one has increased demands for computerized literature searches and for specialized help in some subject areas. Librarians, of course, learn much about both their resources and their patrons in the process of seminar preparation. Finally, it appears that the seminar program is an effective but unobtrusive way to help regular library users adjust to the machine-age library.

Has it been worth the effort? Opinions of the library staff involved in the planning and presenting of the seminars are definitely positive, although there is an acknowledgment of the large amount of time spent on preparation and on publicity. Those librarians skeptical of the benefits of library instruction for any group remain unconvinced, despite the good will towards the library and librarians this program seems to be generating. That some sort of continuing education in library usage is needed for advanced researchers is beyond doubt; the kind of series reported here may prove to be a useful, flexible means to provide this group with information and training, particularly as technology continues to transform the library.-Linda de Wit, Agnes Haigh, and Julie Hurd.

Editor's Note: Linda de Wit and Agnes Haigh are reference librarians at Michigan State University, East Lansing; Julie Hurd is science librarian at $M S U$.

\title{
Library Organization Development at Northeastern University
}

\author{
Thomas H. Cahalan, Chair \\ Northeastern University Library \\ Organization Development \\ Study Team
}

A library organization development program is being conducted at Northeastern University, Boston, as a result of a survey of library staff members which indicated a high interest in organizational change. Plans for the program are based on recommendations given in a report of a study of the Management Review and Analysis Program (MRAP), a self-study program designed by the Association of Research Libraries Office of Management Studies and used in more than 20 large academic libraries. ${ }^{1}$ These include giving careful consideration throughout the study to the feasibility of implementing recommendations being developed, having the study team work closely with the Dean of Libraries and Learning Resources, and providing for consultation of $\mathrm{NU}$ administrators, faculty, and students as well as widespread participation of library staff.

The first phase of the program includes selected modules of the Academic Library Development Program (ALDP), a self-study program designed by ARL/OMS for use in medium-sized academic libraries. Because of plans for an architectural competition for the design of a new central library facility, it is focusing on desired organizational changes with implications for the design of the new facility. Funds for this phase, to be completed by March 1982, are being provided by the National Endowment for the Arts Design Arts Program on a matching basis in consideration of funds being spent by NU for the design competition and in accordance with NEADAP policy of fostering excellence in design by promoting design competitions. Jeffrey J. Gardner of ARL/OMS is serving as the organization consultant for this phase, and an internal study team to direct the self-study is chaired by Thomas $\mathrm{H}$. Cahalan, assistant librarian for acquisitions.

The first two units of the study have been concerned with planning for integration of the individual libraries in the new facility and planning for integration of various reference services now segregated because of the design of the present main library building. Reports of both of the task forces involved have been fully accepted for implementation by the library administration.

The method of selection and the composition of the study team provides an interesting model for a library organization development program. In- 
stead of having a separate study team for this purpose, it was decided to have the study conducted by a pre-existing Library Joint Committee which had been formed to provide liaison between various staff levels. As members of this committee are elected to represent their constituent groups, this arrangement has helped secure support for the organization development program at all levels. It also should provide a use- ful mechanism for reassessment of the work of the present study team and for further study in future years because members of the Library Joint Committee are selected annually.

IE. R. Johnson \& S. H. Mann, Organization Development for Academic Libraries; an Evaluation of the Management Review and Analysis Program. Westport, Conn., Greenwood Press, 1980.

An analysis of the fourth round of Higher Education Act Title II-C research library awards indicates that more institutions are receiving grants than ever before in the program's history. The thirty grants this year include three joint projects, bringing the number of libraries receiving funds to 41 institutions in 25 states. Almost half of the grantees have not previously participated in the program.

Dissatisfaction within the library community about the small number of grants awarded (previously about 23 per year), congressional criticism, and slight changes in the regulations for II-C have all played a part in enlarging the number of participants.

Some potential grantees complained to congressional funding committees with the unfortunate result that in FY 1981 the House refused to go along with the $\$ 1$ million increase requested by the Carter Administration, and funding for II-C remained at $\$ 6$ million. More constructively, concerns were voiced to the congressional authorizing committees which have the power to make changes in the workings of the program. When the Higher Education Act was extended last year in PL 96-374, no statutory changes were made in II-C, but the senate Labor and Human Resources Committee report (S. Rept. 96-733) on the legislation indicated the committee believed that at least 50 grants should be made and that the same small number of institutions should not continue to receive grants year after year.

The one substantive change in the "interim" final regulations for II-C published last December was a change in the selection criteria to conform with the Education Division General Administrative Regulations (EDGAR). The EDGAR criteria shifted the point balance from the previous 60 points for significance as a major research library and 50 points for the nature of the project, to 48 points for eligibility and 62 points for the project itself. Since then, the II-C regulations have undergone further review, and a new set of proposed revised regulations will be published soon for public comment.

These combined influences have called for a larger number of grants, and this year's results (funds received by 41 institutions compared with last year's 27 on the same amount of funds--\$6 million) indicate that the Education Department has been responsive.

Academic and research librarians should watch for the new regulations which will be published in the Federal Register, and comment on their effectiveness and the degree to which they implement the purposes of the program. Those purposes are to assist the nation's major research libraries "in maintaining and strengthening their collections, and in making their holdings available to other libraries whose users have need for research materials." 